J. Product. \& Dev., 16(3):307 - 319(2011)

أثر خطط التنمية الاقتصادية على مستويات الأسعار والاستهلاك للسلع

\author{
محمد جابر عامر - سهام عبدالمولى محمد قتنديل \\ قسم الاقتصاد الزراعي ـ كلية الزراعة - جامعة الزقازيق ـ الزقازيق ـ مصر
}

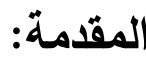

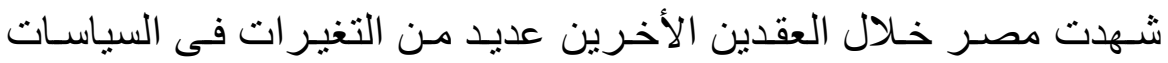

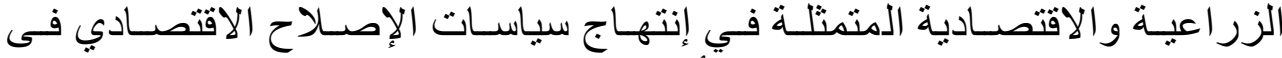

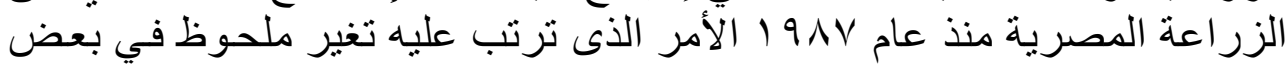

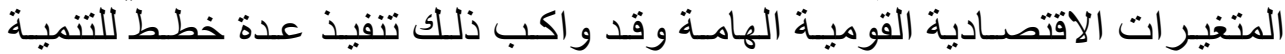

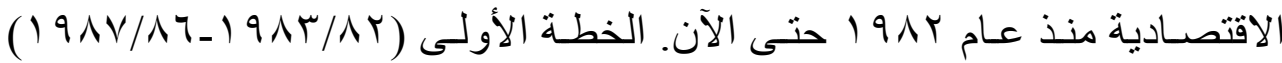

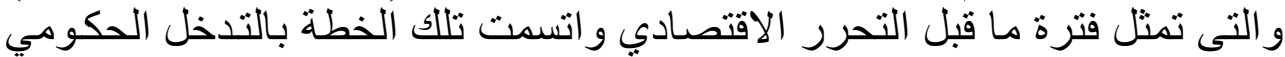

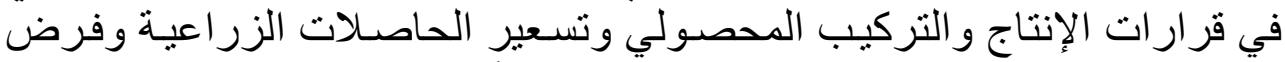

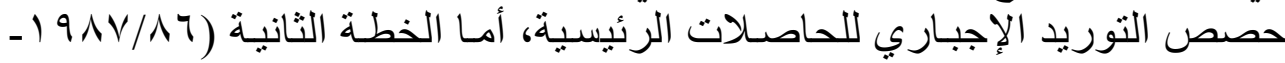

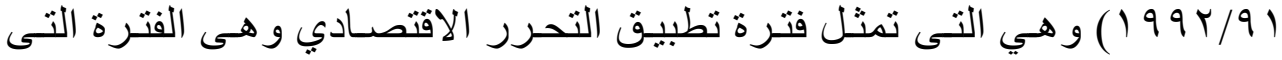

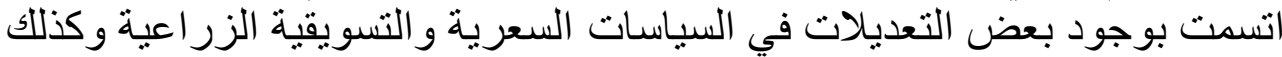

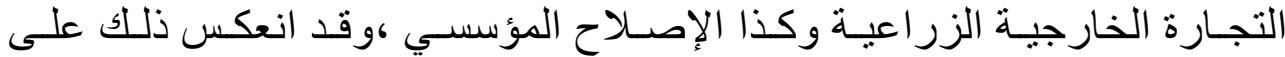

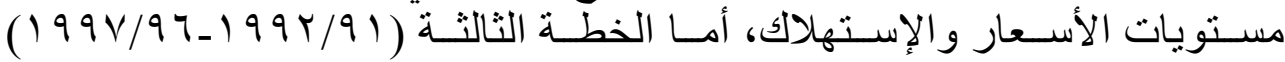

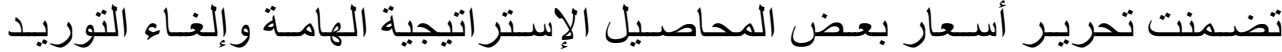

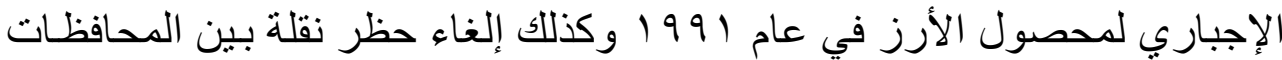

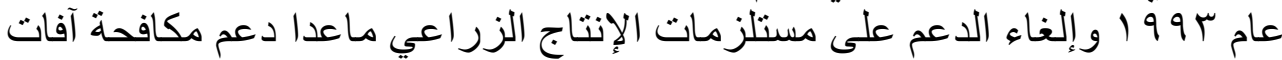

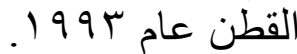

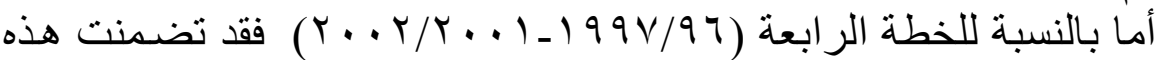

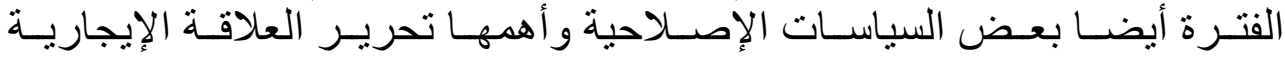

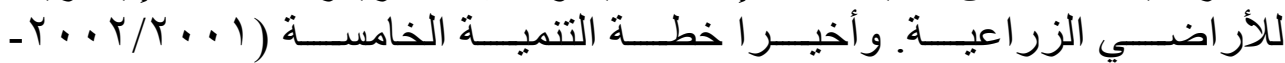

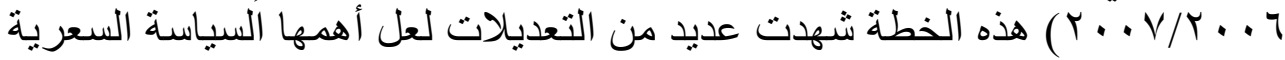

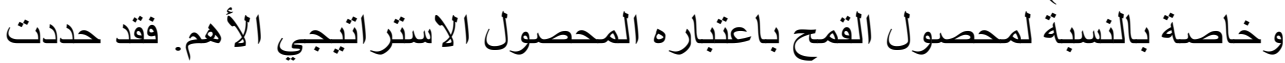

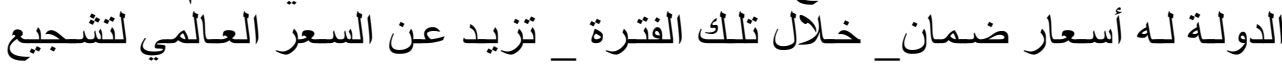
الزراع على زيادة الإنتاج و الانتاجية من القدح.

المشكلة البحثية:

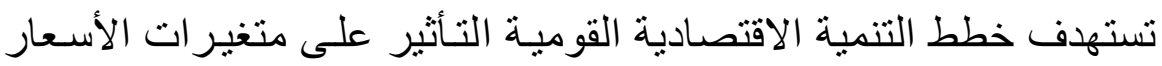
و الاستهلاك وتبين مـن مر اجعـة الدر اسـات السـابقة نقص الدر اسـات التى تناولت الت التهار 
تأثير خطط التنمية القومية على متغير ات الأسعار و الاستهلاك ولذلك تمثلت مشكلة البحث في التعرف على التغير ات السعرية والاستههلاكية في المجمو عات التهية الغذائية

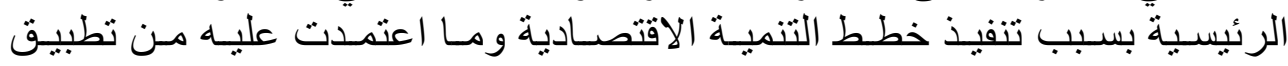

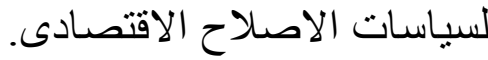

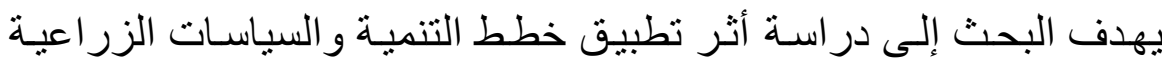
هدف البحث:

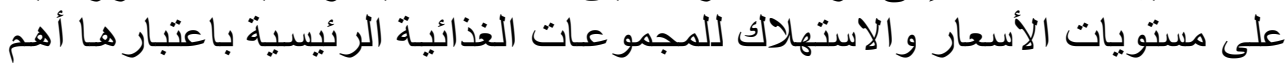

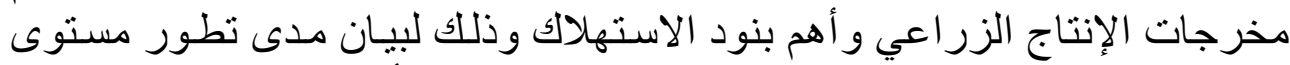

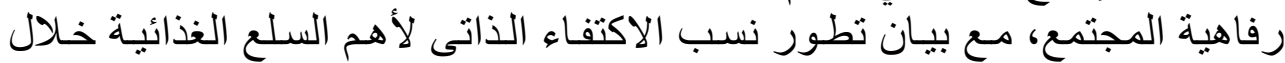
فترة تنفيذ تلك الخطط.

\section{مصادر البيانات وطرق التحليل:}

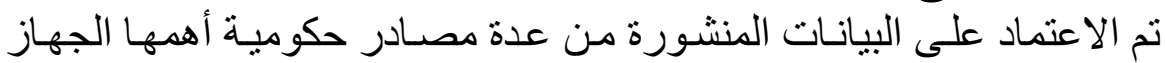

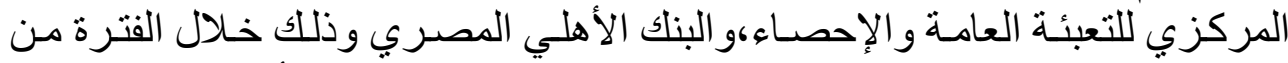

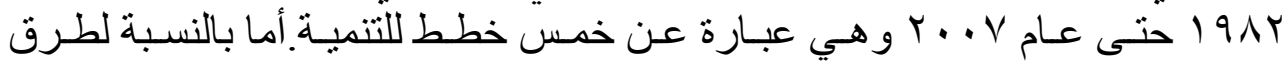
التحليل فقد استخدمت المعادلة رقم (1) فى مقارنة نسب الاكتفاء الذاتى و التى شملت الته

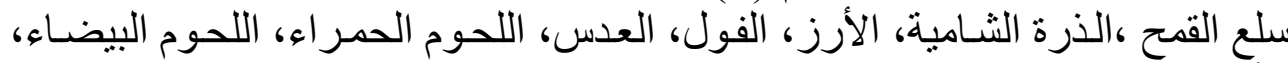

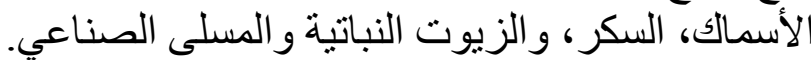

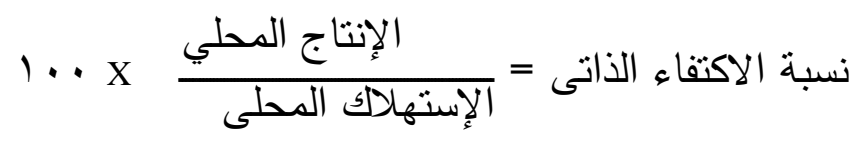

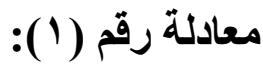

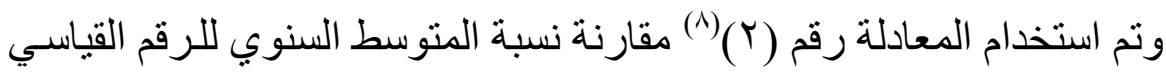

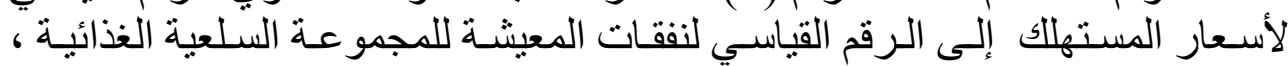

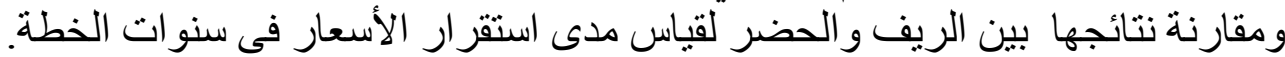

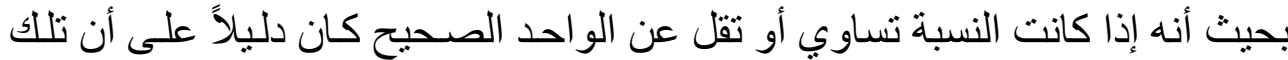

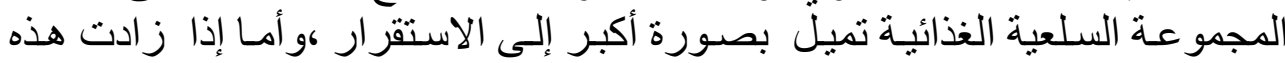

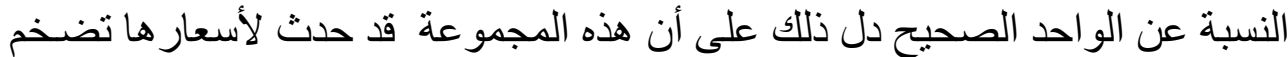

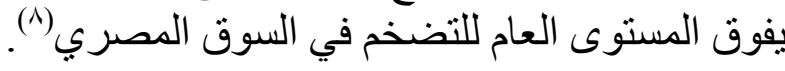

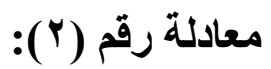

المتوسط السنوي للرقم القياسي لسعر المستهلك (هـ)

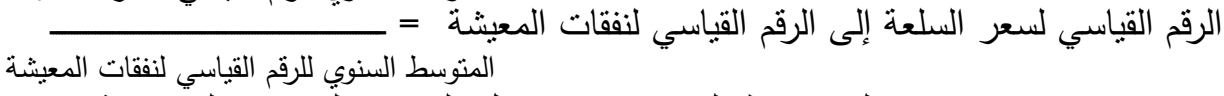

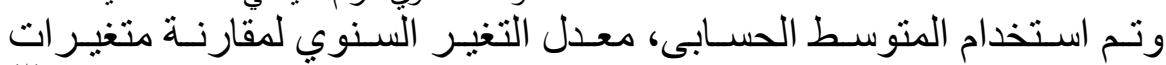

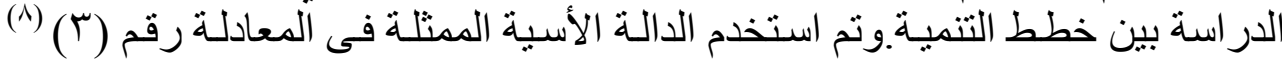
لقياس معدل النمو السنوي. 
$r=\frac{\operatorname{Ln}\left(y_{t}\right)-\operatorname{Ln}\left(y_{0}\right)}{t}$

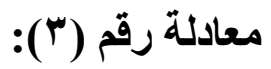

y معدل النمو السنوي للمتغير : r

حيث:

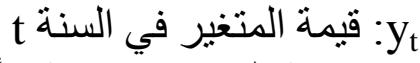

: قيمة المتغير في سنة الأساس في المنة :

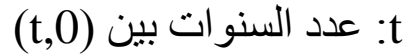

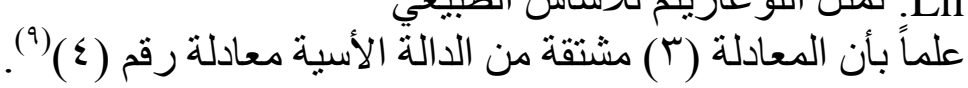

$$
y_{t}=y_{o} e^{r t}
$$

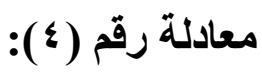

وفي تحليـل اتجـاه الأسـعار تم استخدام المتوسط السـوي للـرقم القياسـي

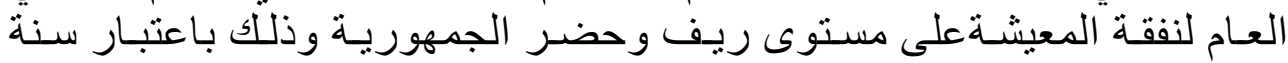

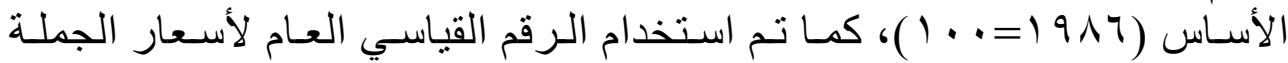

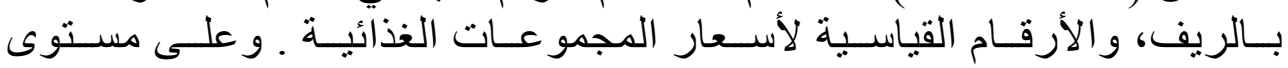

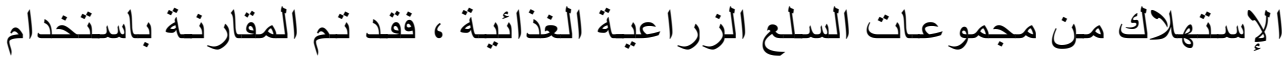
متوسط نصيب الفرد بالكيلو جر ام فى السنة وكذلك معدلات الته الته النمو داخل كل خطة.

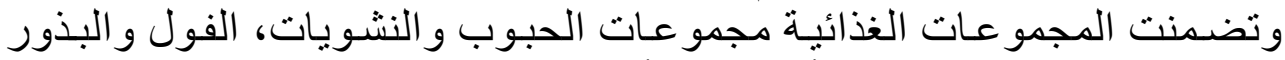

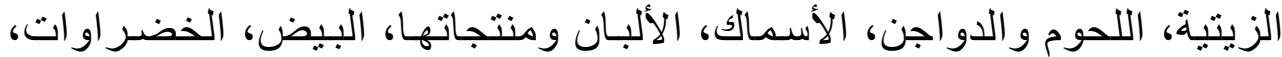

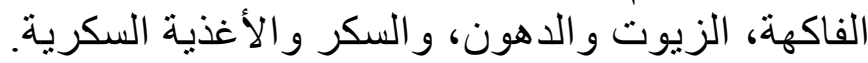

\section{النتائج والمناقشة:}

الاختلافات السعرية خلال خطط التنمية الاقتصادية:

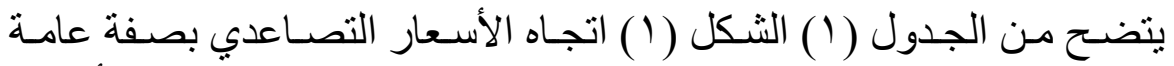

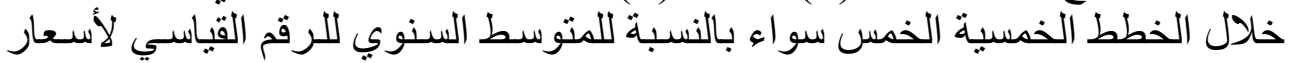

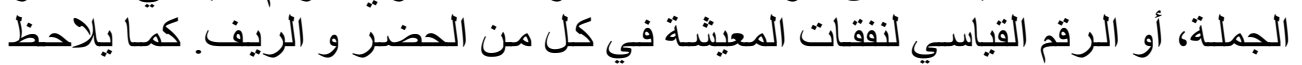

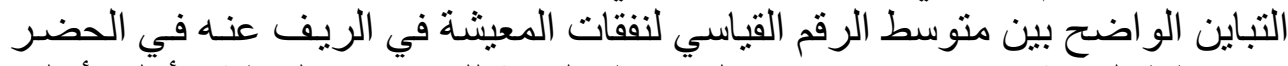

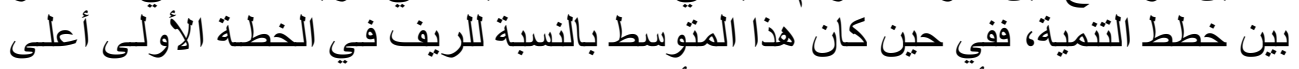
منه في الحضر، إلا أنه في الحضر كان أعلى منه في الريف في باقي الخطط، وذللك التكى 
جدول (1) : المتوسط السنوى ومعدل النمـو السنوي في الـرقم القياسـي لأسـعار

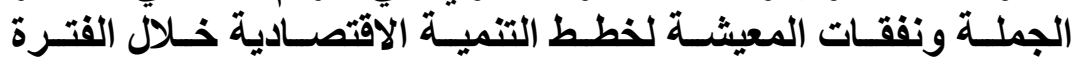

\begin{tabular}{|c|c|c|c|}
\hline & & \multicolumn{2}{|c|}{.$\left(Y \cdot V_{-} \mid q \wedge r\right)$} \\
\hline معدل التغير & السنوسط & 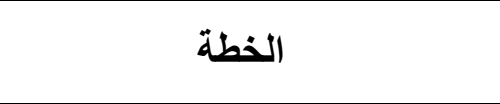 & مؤشر التتمية \\
\hline $1 \cdot .1$ & $\vee \wedge .7$ & 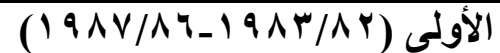 & \\
\hline 14.0 & $r \cdot 1.1$ & الثانية ( & \\
\hline$\varepsilon .1$ & MrV & 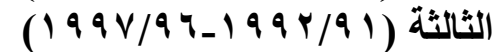 & \\
\hline r & $r \wedge \varepsilon .0$ & 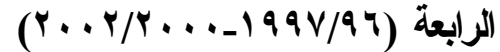 & \\
\hline 9.9 & $91 r . r$ & 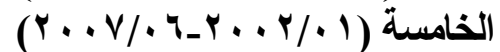 & \\
\hline 14.7 & VY.q & 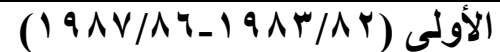 & \\
\hline ir & IAr.r & 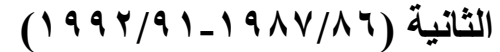 & \\
\hline $7 . \wedge$ & rYV.O & 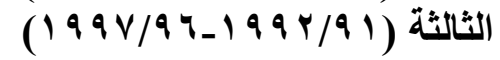 & 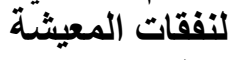 \\
\hline r & $\varepsilon 19$ & 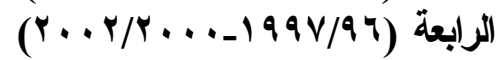 & في الحض \\
\hline 1.9 & 7.1 .9 & 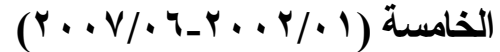 & \\
\hline 1Y. & $V \leqslant . V$ & الأولى ( & \\
\hline $1 Y .7$ & $1 \wedge 1 . \wedge$ & الثانية ( & \\
\hline 7 & $r \cdot V . \varepsilon$ & 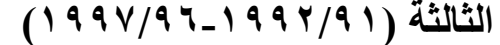 & ل ل ل النقةات المع \\
\hline $1 . \wedge$ & rvq & 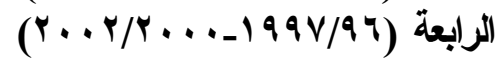 & فى الريف \\
\hline 9.1 & $0 \leq r . V$ & 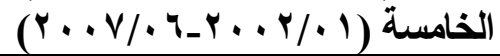 & \\
\hline
\end{tabular}

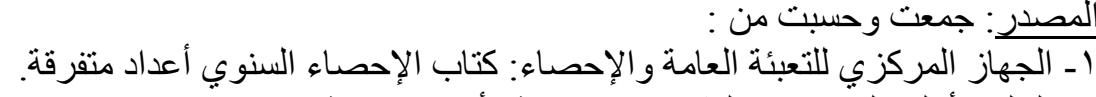

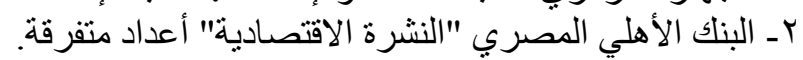

تطور الأرقام القياسية لأسعار الجملة والرقم القياسى لنفقة المعيشة فى الحضر والريف

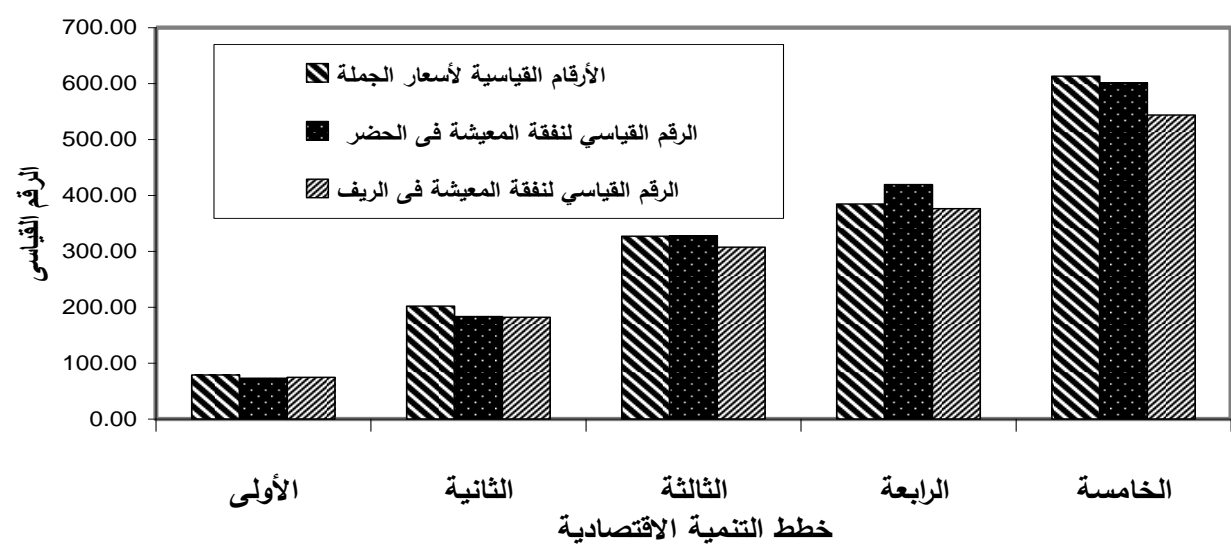

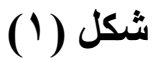




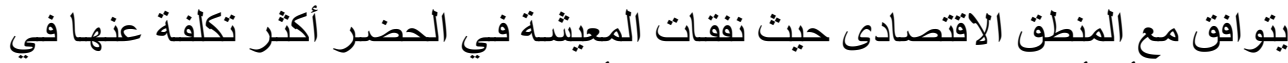

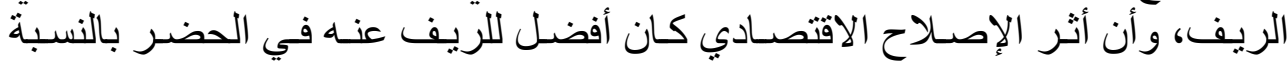

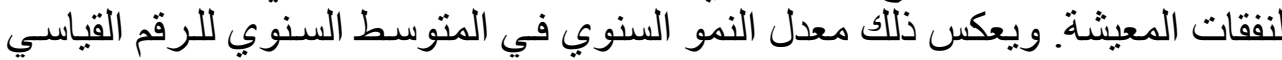

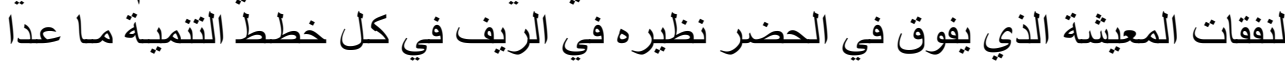

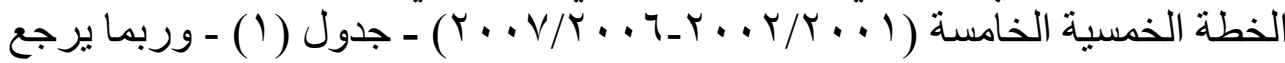

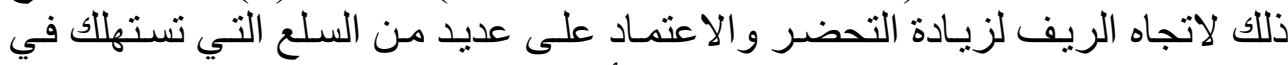

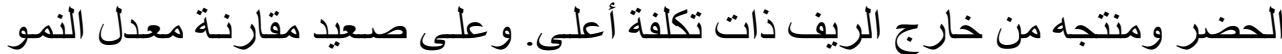

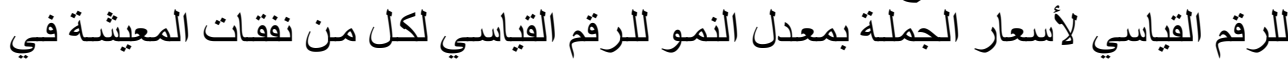
وفي الحضر، يتبين انخفاض هذا المعدل في الخطط الخمسية الأربع الأولى اليق

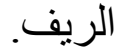

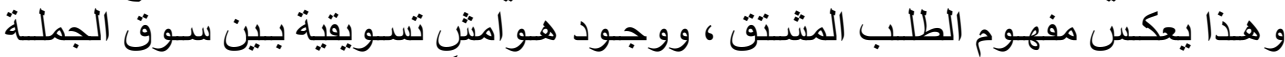

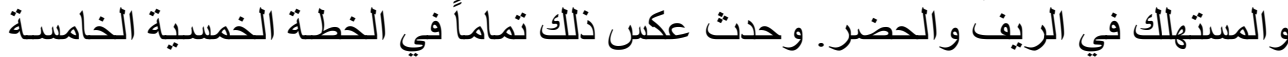

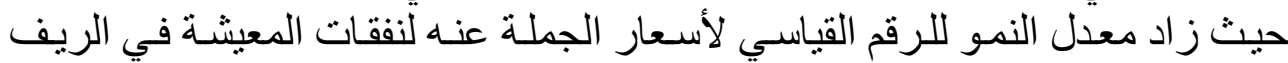

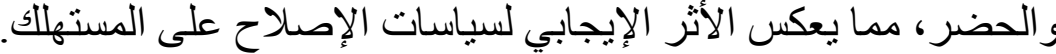

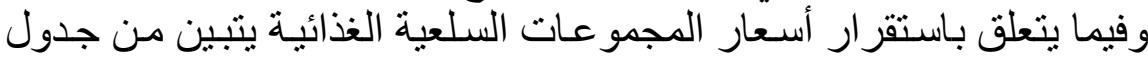

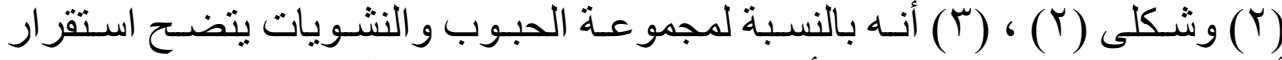

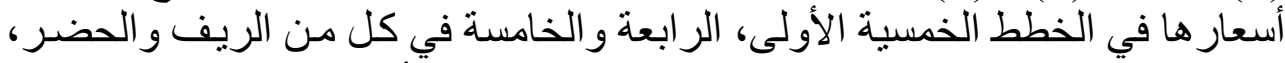

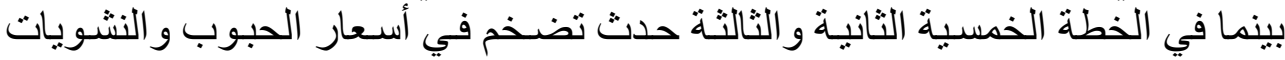

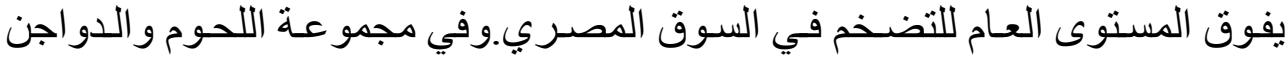

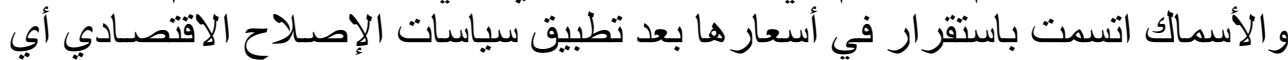

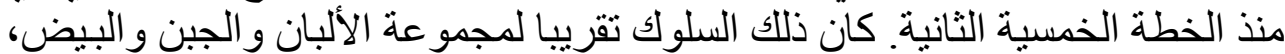

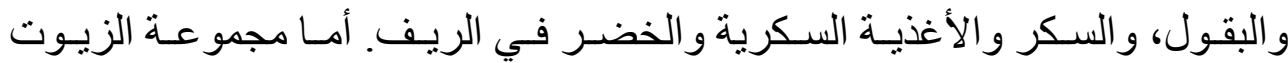
و الدهون فتتسم في الحضر بعدم استقر ار أسعار ها في كل الخطط الخط الخمسية الخمس، أمسا

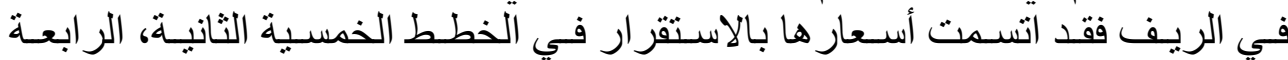

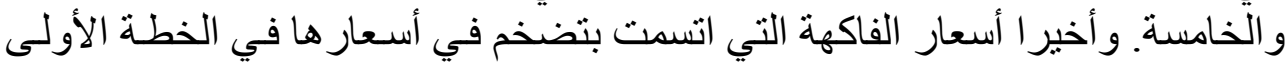

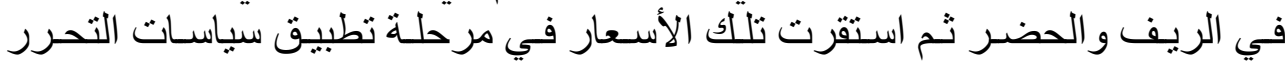

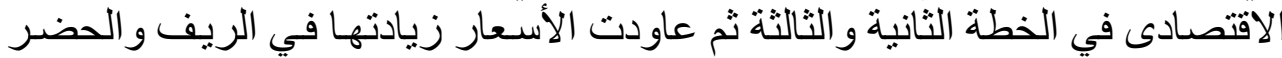

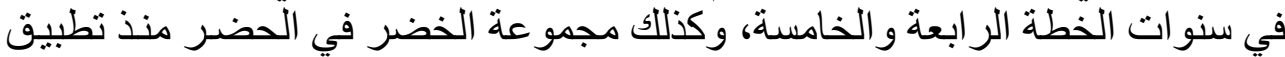

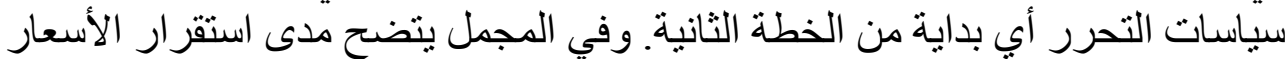

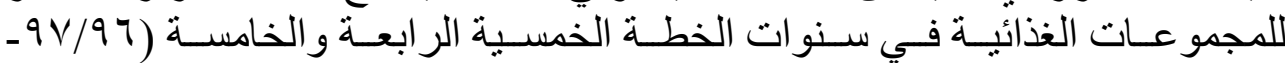

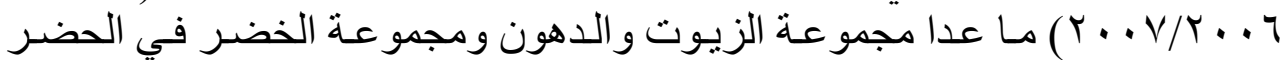

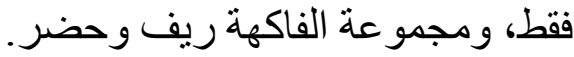

تطور نسب الاكتفاء الذاتي ونصيب الفرد السنوى من المجموعة الغذائية:

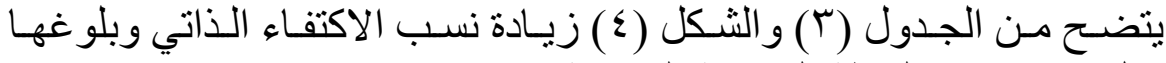

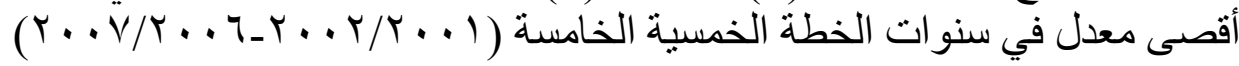


جدول (ץ): أثر خطط التميـة الاقتصـادية على استقرار أسعار السـلع الغذائية في

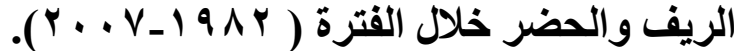

\begin{tabular}{|c|c|c|c|}
\hline \multicolumn{2}{|c|}{ 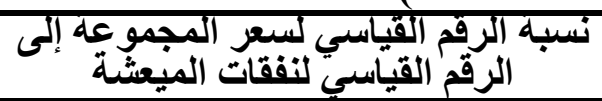 } & \multirow[t]{2}{*}{ الخطة } & \multirow{2}{*}{ المجموعة الغذائية } \\
\hline حضر & ريف & & \\
\hline 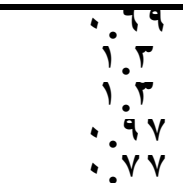 & 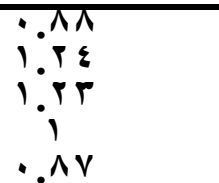 & التالتانتيهية & الحبوب والنشويات \\
\hline $\begin{array}{l}\qquad 11 \\
\because 97 \\
995 \\
998 \\
919\end{array}$ & 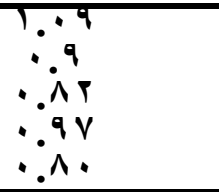 & الآلتآتآتيلية & واللدوم الحمر والأسماك \\
\hline 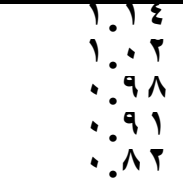 & $\begin{array}{l}\because q 5 \\
\because \wedge q \\
\because 9 q \\
\because 9 T\end{array}$ & الآلتانتيّية & الألبان والجبن و البيض \\
\hline 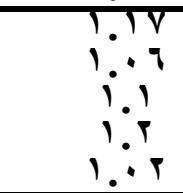 & 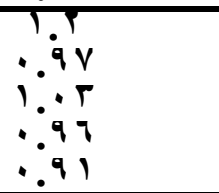 & الألتانتِّيَ & الزيوت والدهون \\
\hline 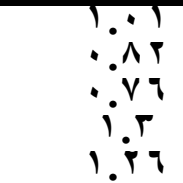 & 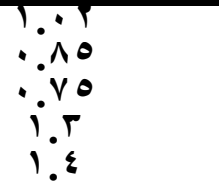 & 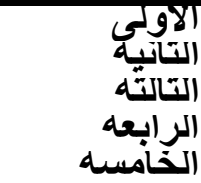 & الفاكهة \\
\hline $\begin{array}{l}\because \because q \\
\because \because 8 \\
\because \wedge 0 \\
\because \wedge 1 \\
\because \wedge T\end{array}$ & $\begin{array}{l}\because \because 9 \\
\because \because 4 \\
\because \because 4 \\
\because \because 4\end{array}$ & 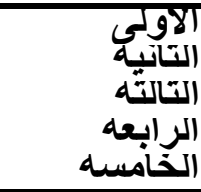 & الخضر \\
\hline $\begin{array}{l}\because 91 \\
\because 97 \\
995 \\
990 \\
998\end{array}$ & 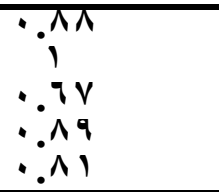 & الالتانتِّيَ & البقول \\
\hline 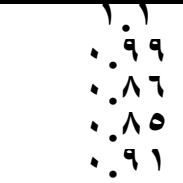 & $\begin{array}{l}\because 11 \\
\because 91 \\
\because 98 \\
\because 99\end{array}$ & 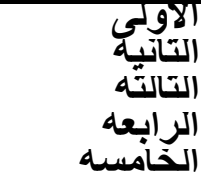 & السكرية الأغذية \\
\hline
\end{tabular}

المصدر: جمعت وحسبت من بيانات: ا- الجهاز المركزي للتعبئة العامة والإحصاء: كتاب الإحصاء السنوي أعداد متقرقة. r- الجهاز المركزي للتعبئة العامة والإحصاء: نشرة الأرقام القياسية، أعداد مثقرقة.

المتوسط السنوي للرقم القياسي لسعر المستهلك للمجموعة السلعيةهـ

المتوسط السنوي للرقم القياسي لنفقات المعيشة 
خطط خلال الريف فى الغذائية للمجموعات المستهلكين لأسعار القياسية الأرقام تطور

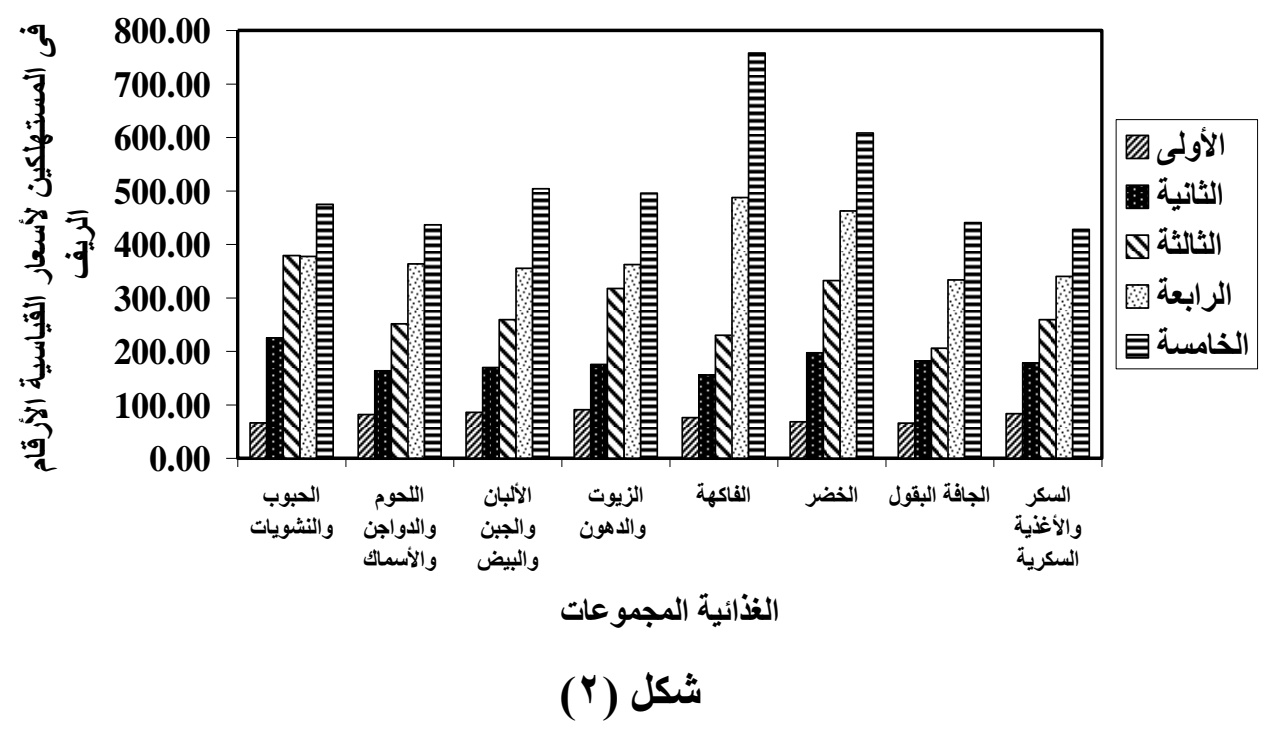

التنمية خطط خلال الحضر فى الذذائية للمجموعات المستهلكين لأسعار القياسية الأرقام تطور

الاقتصادية

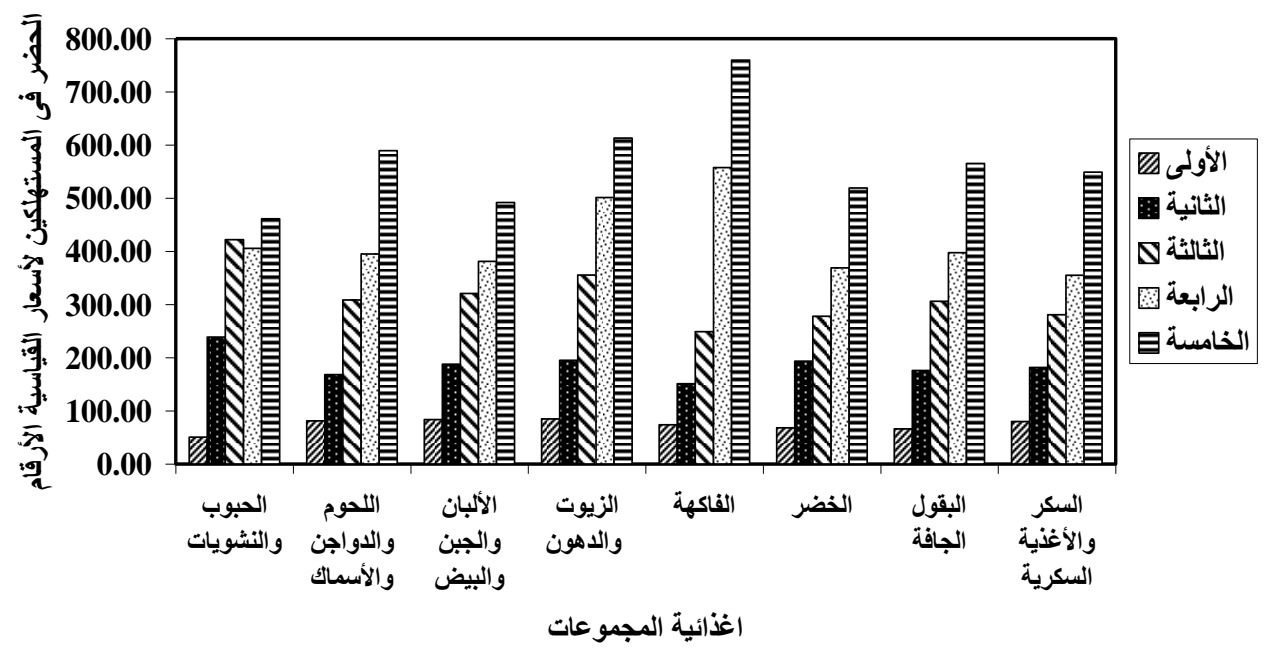

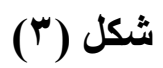




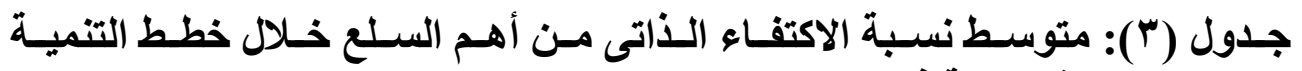

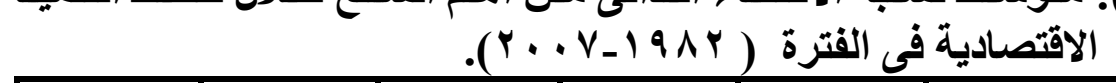

\begin{tabular}{|c|c|c|c|c|c|}
\hline الخامسة & $\begin{array}{c}\text { الرابعة } \\
\text { (\%) }\end{array}$ & $\begin{array}{l}\text { الثالثة } \\
\text { (\%) }\end{array}$ & $\begin{array}{l}\text { الثانية } \\
\text { (\%) }\end{array}$ & $\begin{array}{c}\text { الأولى (\%) } \\
\end{array}$ & الخطة \\
\hline $7 Y$ & 01.9 & $\theta \leqslant . r$ & r^.9 & $Y 1 . \Lambda$ & القمح \\
\hline $7 Y .7$ & $01 . V$ & $7 r .2$ & 74 & $0 \xi$ & الأرة الشامية \\
\hline $1 Y \cdot .1$ & $1 \varepsilon \cdot . Y$ & 110.1 & 1.7 .1 & ITH.r & الأرز \\
\hline$\varepsilon 0.1$ & $\vee \wedge .7$ & $1 \cdot Y . \varepsilon$ & $\Lambda 7 . \Lambda$ & $1 Y \cdot .1$ & الفول \\
\hline Y. & $7 . Y$ & $1 \% . \varepsilon$ & 17.7 & rY & العدس \\
\hline$V V .9$ & $V Y . \varepsilon$ & $\vee V . \wedge$ & $V \varepsilon . Y$ & $V \cdot . \Lambda$ & اللحوم الحمراء \\
\hline 99 & $1 \ldots$ & $1 \ldots$ & 91.1 & $\vee \wedge$ & اللحوم البيضاء \\
\hline$\Lambda \varepsilon . \Gamma$ & V $7 . \Lambda$ & $\overline{V T . \varepsilon}$ & $v \cdot .7$ & $7 V . V$ & الأسماك \\
\hline 19.0 & VY.A & 77 & 77 & $0 \leqslant . r$ & السكر \\
\hline $\mid Y 1.1$ & or.z & OV.Y & VY.A & 71 & والزيوتي الصناعية \\
\hline
\end{tabular}

المصدر: جمعت وحسبت من بيانات:

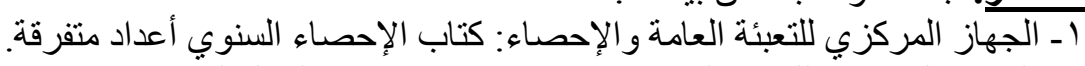

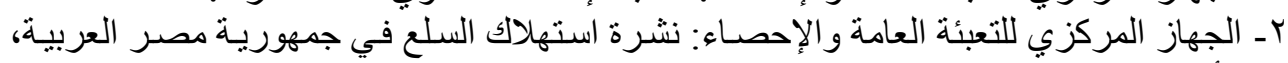

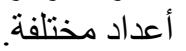

r- البنك الأهلي المصري "النشرة الاقتصادية" أعداد متفرقة.

نسبة الاكتفاء الذاتى من أهم السلع الغذائية خلال خطط التنمية الاقتصادية

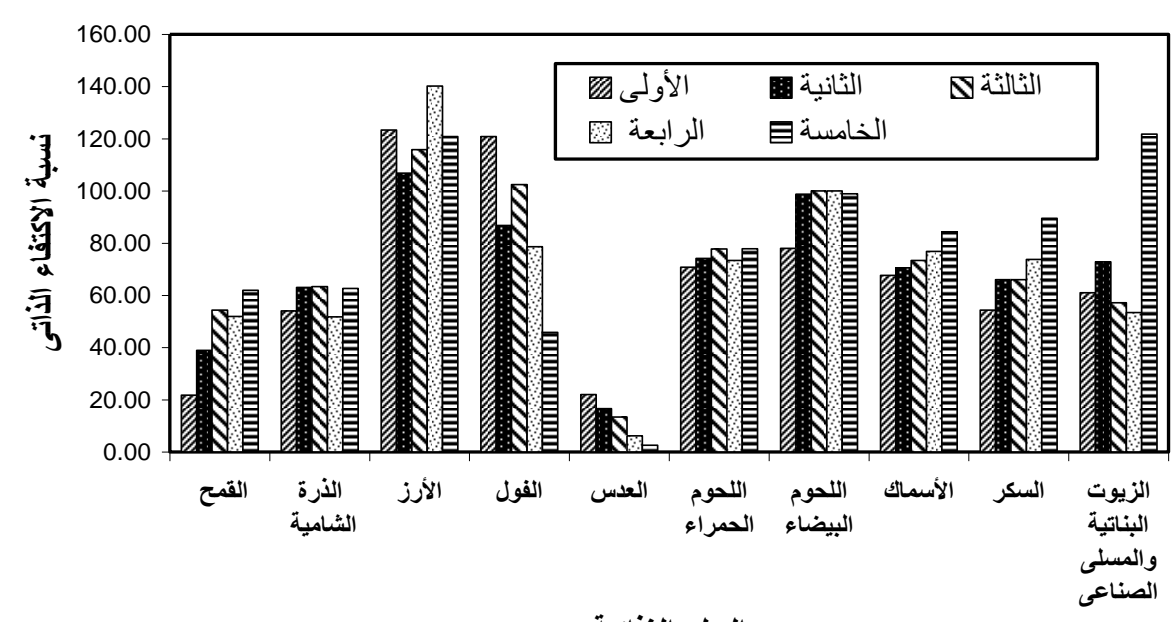

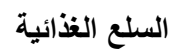

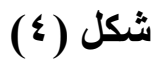


لسلع القمح، اللحوم الحمر اء، الأسماك، السكر و الزيوت والكو والدهون. أمـا بالنسبة

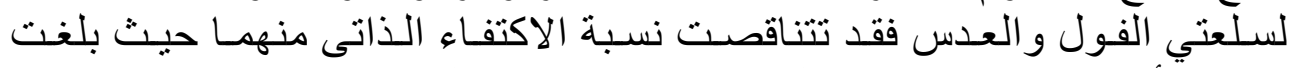

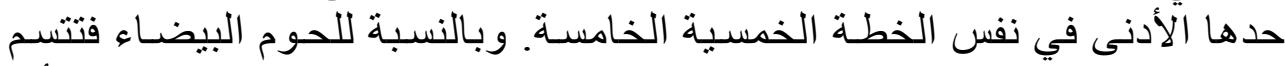

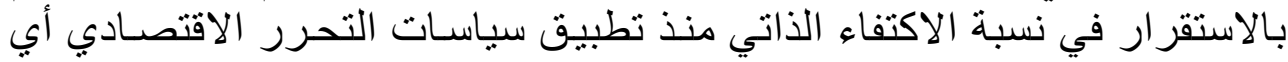

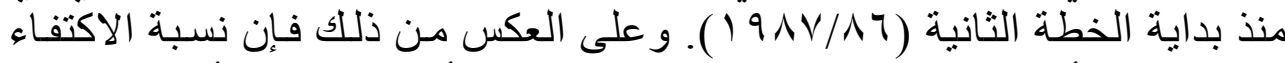

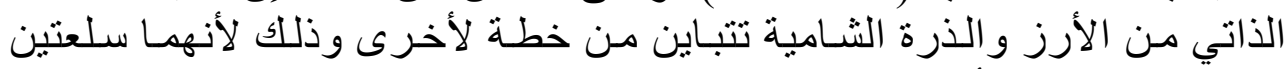

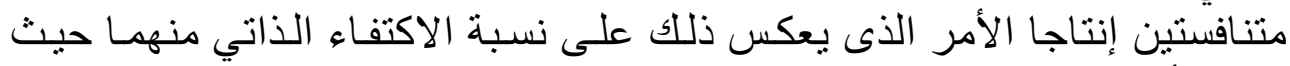

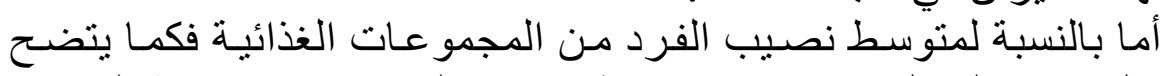

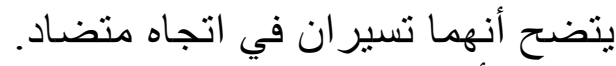

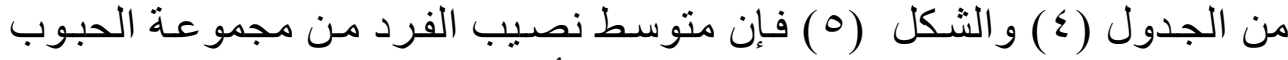

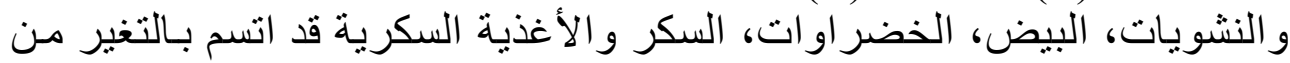

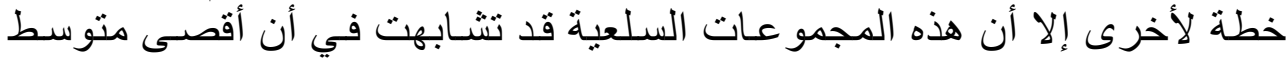

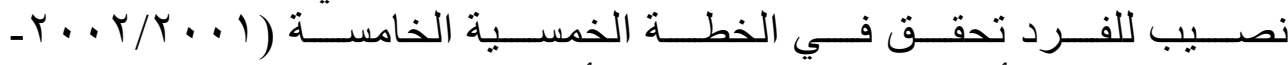

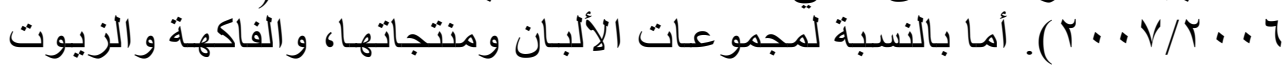

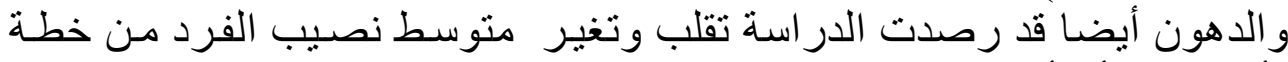

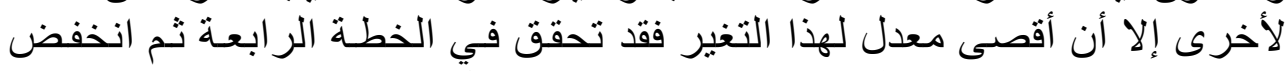

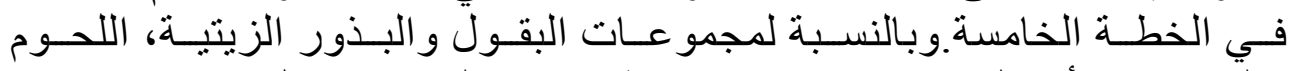

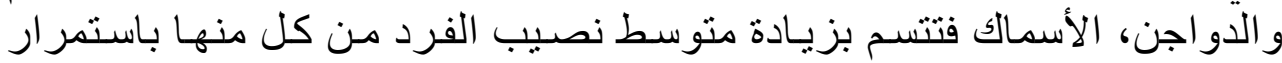
ويصل أقصاه في الخطة الخمسية الخامسة.

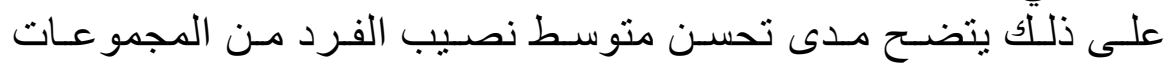

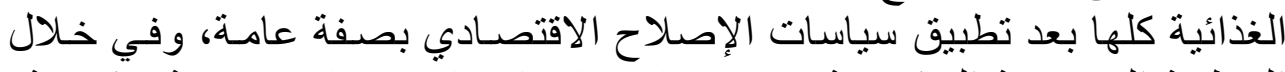

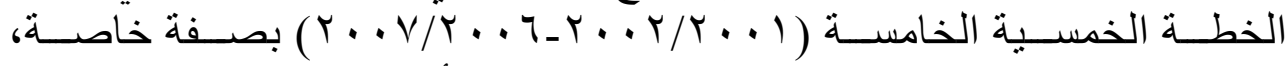

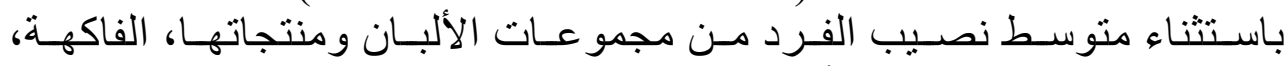

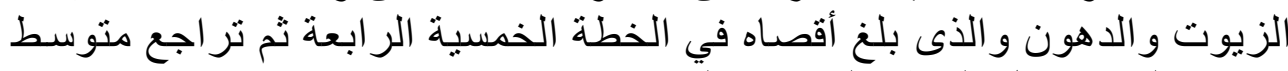
نصيب الفرد خلال الخطة الخمسية الخامسة.

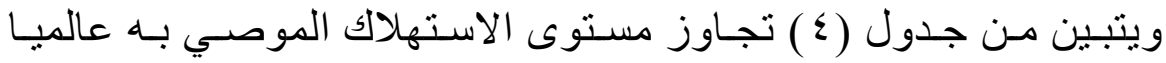

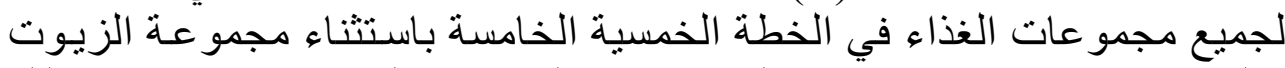

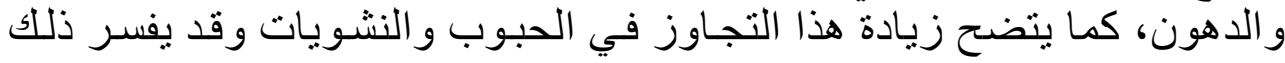

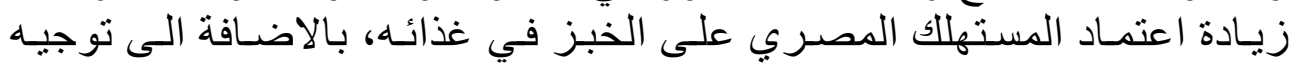
جزء كبير للاستهلاك الحيو اني. 
نصيب الفرد فى السنة من المجموعات الفذائية بالكيلو جرام خلا خطط التنمية الاقتصادية

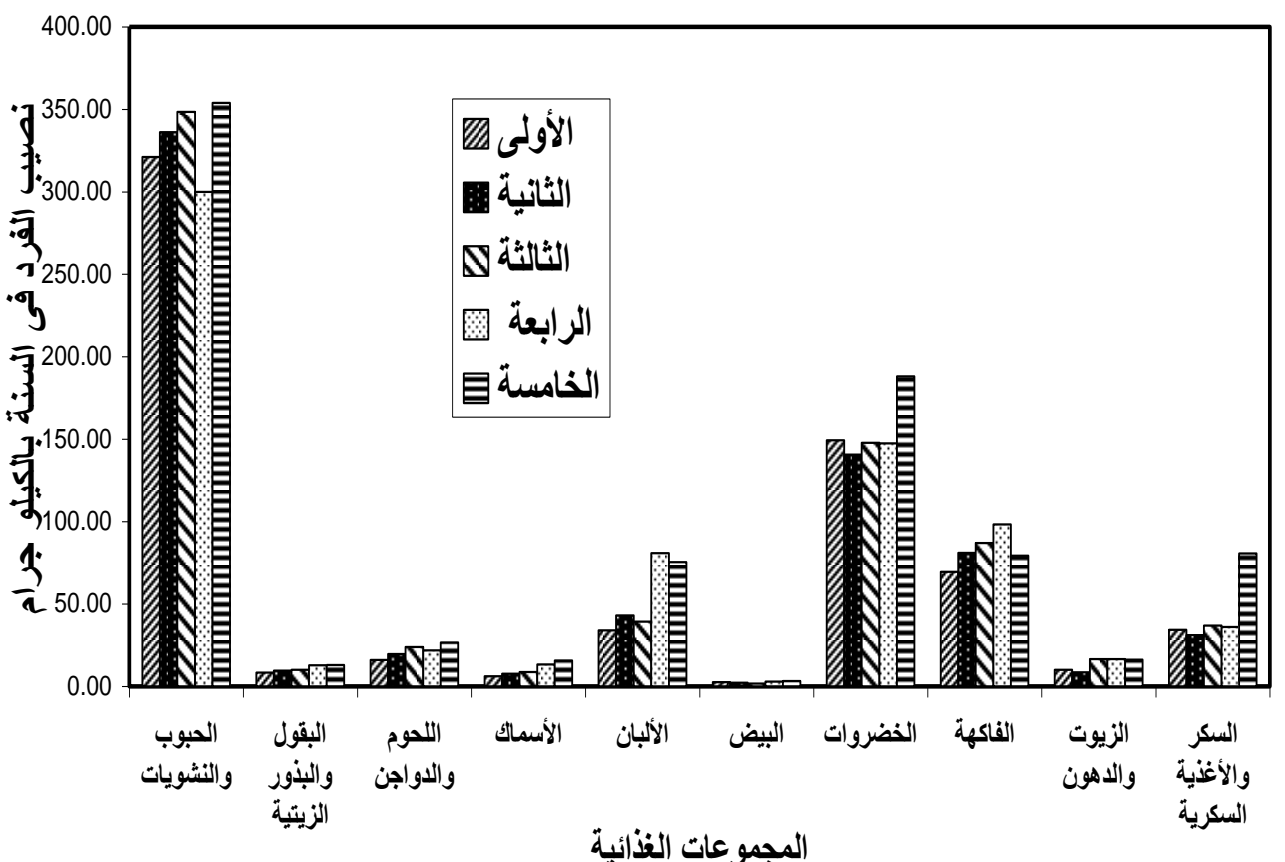

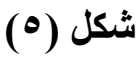

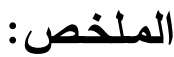

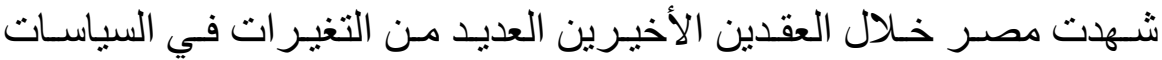

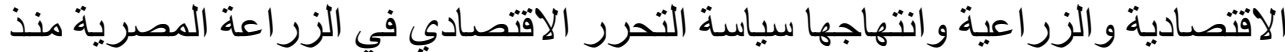

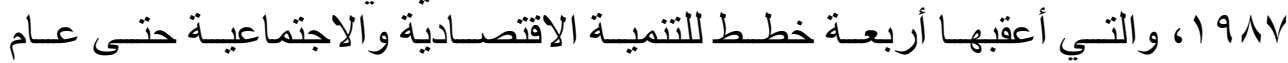

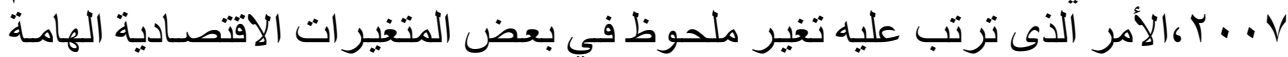

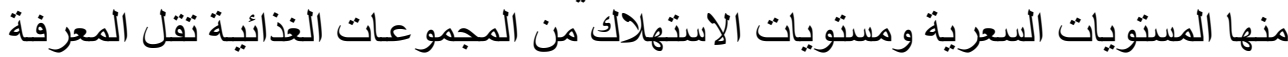

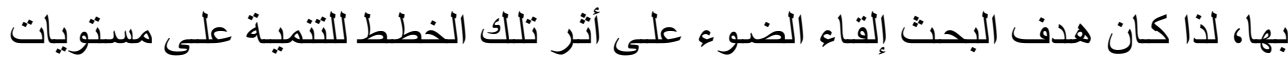

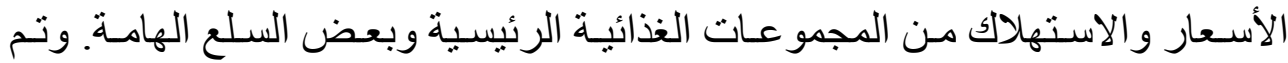

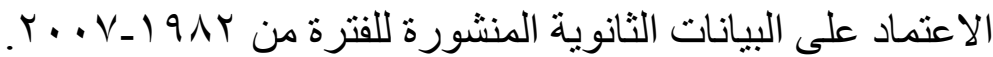

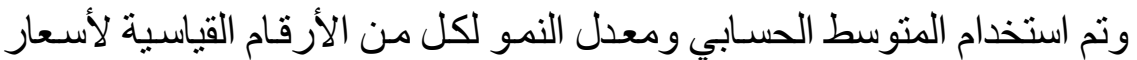

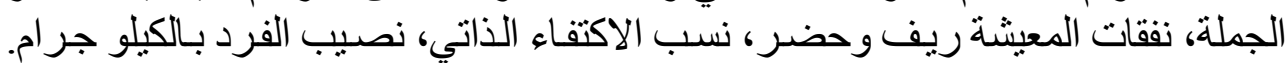

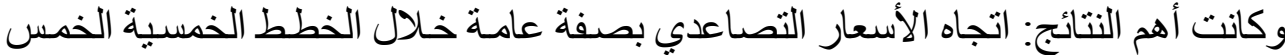

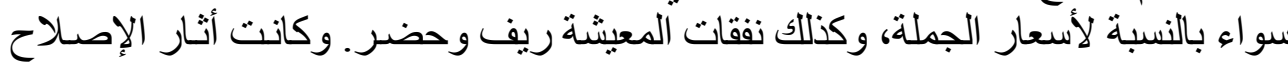

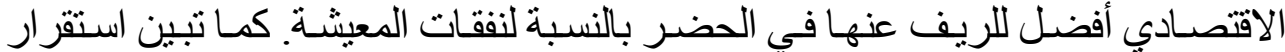
الأسعار للمجمو عات الخذائية في سنوات الخي الخطة الخمسية الرابعة. 
جدل (\&): معل النمو السنوى ومتوسط نصيب الفرد في السنة من المجموعات الذذائية بالكيلو

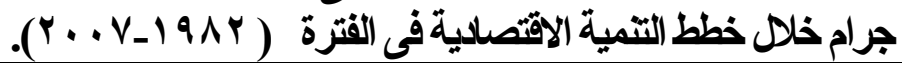

\begin{tabular}{|c|c|c|c|c|}
\hline المتوسط الموصى به & 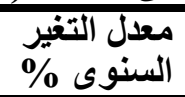 & المتوسط & الخطة & مؤشر التنمية \\
\hline 199.0 & 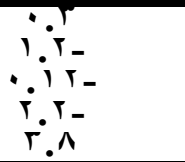 & $\begin{array}{l}\text { rot } \\
r r 7 \\
r \geq 1.2 \\
r 99 . \wedge \\
r 0 r . \wedge\end{array}$ & 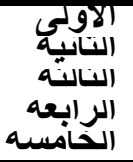 & والنشبوبِيات \\
\hline$\Lambda .0$ & 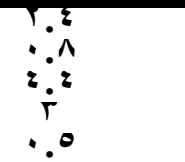 & $\begin{array}{l}1.2 \\
9: 7 \\
19.7 \\
179 \\
1 \%\end{array}$ & الالإليّية & ألزّة \\
\hline \multirow{3}{*}{ \& $\leqslant\}}$. & $\begin{array}{l}0.0 \\
r .5 \\
94- \\
v .4 \\
1 . \wedge\end{array}$ & $\begin{array}{l}79 \\
19.7 \\
15.9 \\
17.1 \\
17.7\end{array}$ & الالآلياية & \\
\hline & $\begin{array}{l}7 \\
1.7 z- \\
0 . z \\
0 \% \\
0\end{array}$ & 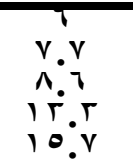 & الخالتيّي & الأسس \\
\hline & $\begin{array}{l}i^{2} \\
i- \\
i i_{-} \\
i .1 \\
i_{-}\end{array}$ & 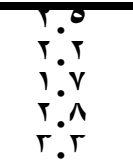 & الألإيلية & \\
\hline$V \varepsilon . \wedge$ & $\begin{array}{l}r^{2} \\
\hat{v}^{2}- \\
\because v^{7} \\
\because \wedge\end{array}$ & 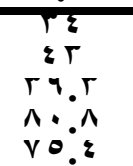 & 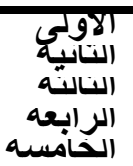 & \\
\hline$\vee 9 . \wedge$ & $\begin{array}{l}\because y^{\prime} \\
\because v_{-} \\
\because r^{4}\end{array}$ & 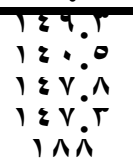 & الناليّية & ـاوات \\
\hline$V \varepsilon . \wedge$ & $\begin{array}{l}1.0 \\
\because \mathrm{v}- \\
1.2 \\
1.2 \\
1.7-\end{array}$ & $\begin{array}{l}74.0 \\
1.94 \\
10 \\
41 \\
14.5\end{array}$ & الألاوليهي & الفاك \\
\hline rV.\& & $\begin{array}{l}0 . v- \\
10- \\
10.2 \\
1 . \dot{r}_{-} \\
1.7\end{array}$ & 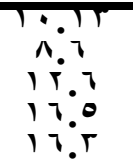 & الألإيلية & والزيوت \\
\hline r.. & 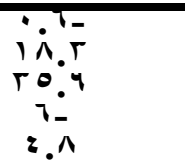 & $\begin{array}{l}r z i \\
r i \\
r v \\
r 7 \\
\Lambda \cdot . v\end{array}$ & الألأيليّي & \\
\hline
\end{tabular}

المصدر : جمعت وحسبت من بيانات:

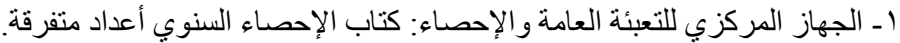

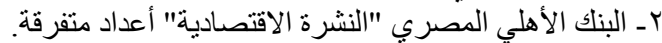

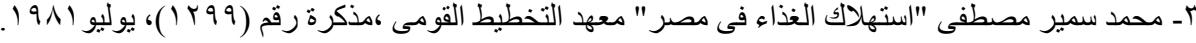




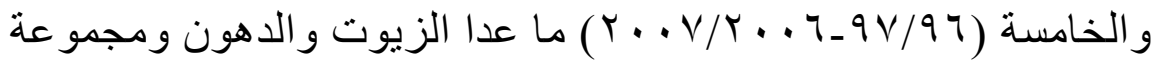
الخضر في الحضر فقط،ومجموعة الفاكهة ريف وحضـر التي اتسمت بالتضـخم

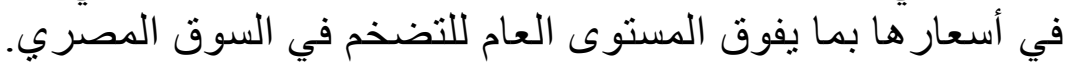

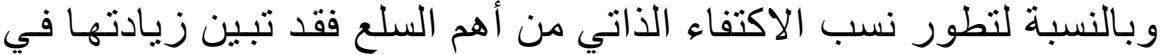

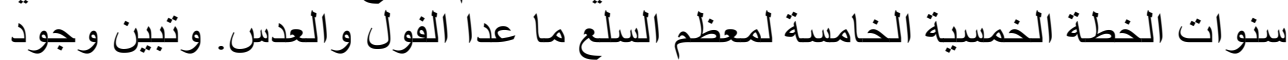

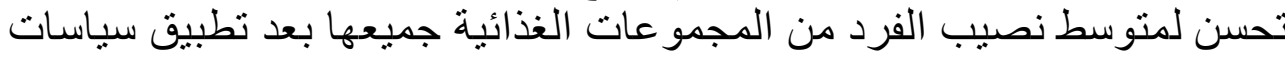

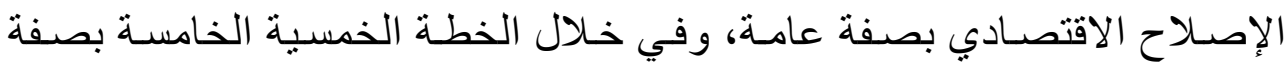

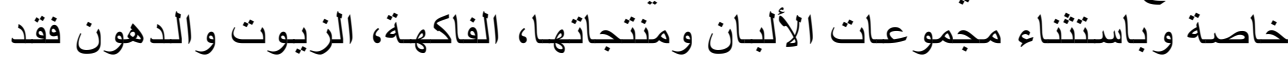

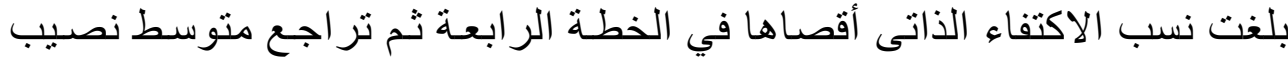

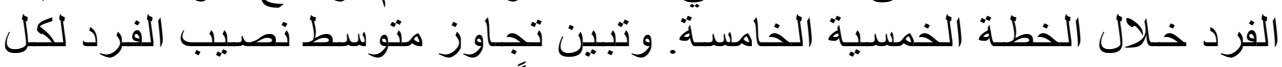

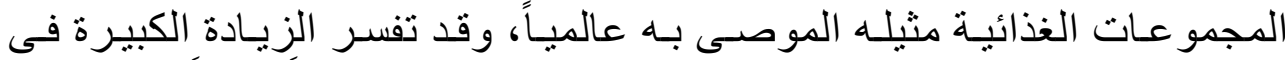

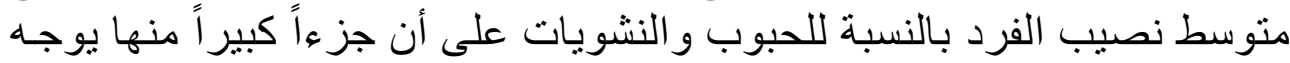

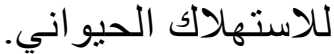

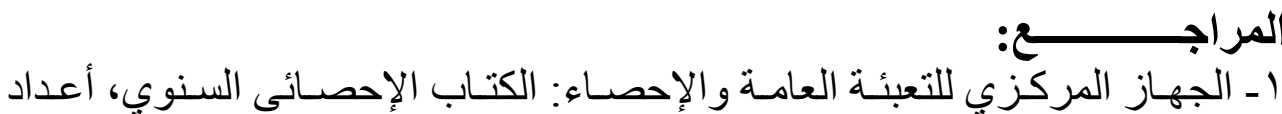
مختلفة

Yـ الجهاز المركزي للتعبئة العامـة والإحصـاء: نشـرة استهلاكك السـلع في جمهوريـة مصر العربية، ألعداد مختلفة.

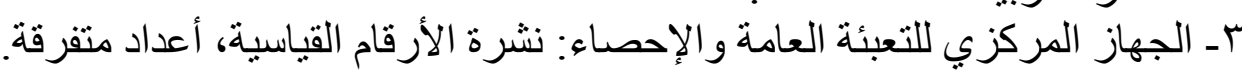

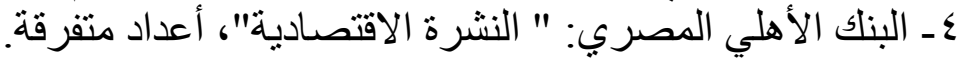

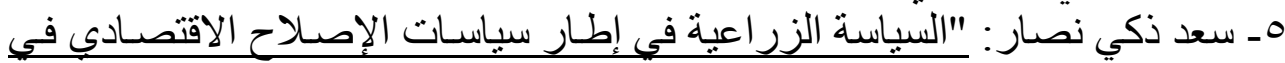

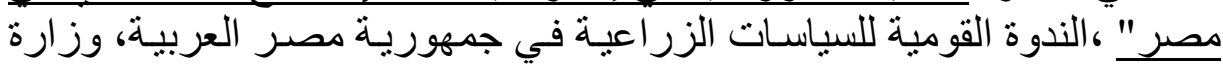

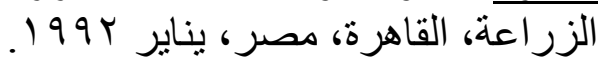

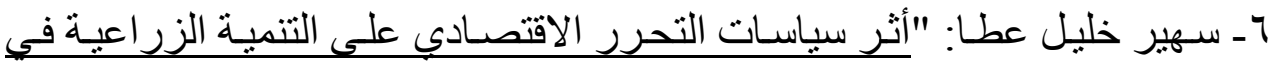

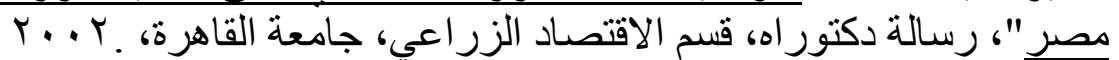

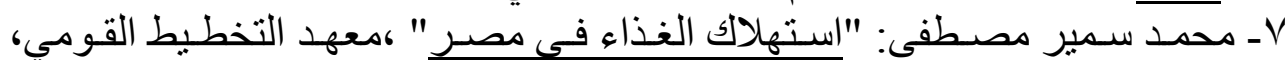

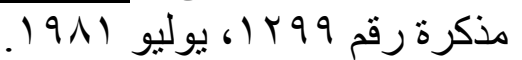

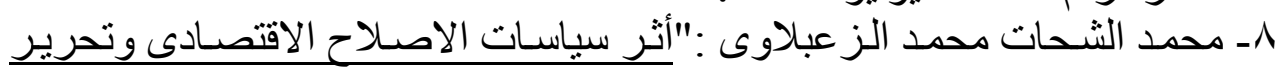

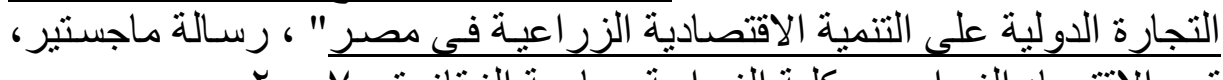

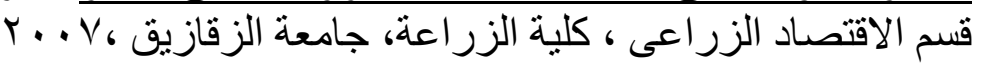

9- Alpha Chaing : "Fundamental Methods of Mathematical Economics ", Second Edition. McGraw Hill book Company, New York, U.S.A 1972. page :138-156. 


\title{
IMPACT OF ECONOMIC DEVELOPMENT PLANS ON PRICE LEVELS AND CONSUMPTION OF FOOD COMMODITIES
}

\author{
Mohamed G. Amer and Siham A. M. Kandil \\ Department of Agricultural Economics - Faculty of Agriculture - Zagazig \\ University, Zagazig, Egypt.
}

\begin{abstract}
Egypt witnessed during the last two decades, many changes in the agricultural economic policies, and adopted the economic liberalization policy in Egyptian agriculture since 1987, and followed by four plans for economic and social development till 2007, resulting in a noticeable change in some important economic variables such as price levels and consumption levels of food categories, the aim of this research aims at studying the impact of these development plans on price levels and consumption of major food groups and the main commodities. The research depends on secondary data for the period from 1982 to 2007.

The statistical analysis includes the arithmetic mean and the growth rate for each of the wholesale prices indices, rural, urban cost of living indices, the self-sufficiency rate and per capita consumption. The most important results indicated the upward trend of prices in general during the five-year plans for both the wholesale prices, as well as, cost of living in the rural and urban areas. The impact of economic reform, was best for the rural areas than in urban areas for cost living. It also showed the stability of prices of food groups in the fourth and fifth five-year plans (96/972006/2007), except for Oils, Fats and Vegetables in urban areas only, and Fruits in the rural and urban areas, which was characterized by inflation in prices beyond the general level of inflation in the Egyptian market.

For the evolution of self-sufficiency ratio in most important goods found an increase in the fifth five-year plan for most commodities except Beans and Lentils. There is an improvement in the average per capita for all the food categories after the application of economic reform policies in general, and during the fifth five-year plan, in particularly, exception the Dairy products, Fruits, Oils and Fats which reached a maximum in the fourth plan, then an average per capita declined during the fifth five year plan. the average per capita for each food group increased than that recommended internationally, the large increase for cereals and starches may explain that much of it destined for animal feed.
\end{abstract}

Keywords: Economic development plans, price levels, consumption of food commodities. 